\title{
DEVELOPMENT OF AUTOTROPHIC DENITRIFICATION FOR NITRATE-CONTAMINATED INDUSTRIAL WASTEWATER
}

\author{
By : Rudi Nugroho \\ Center for Environmental Technology, BPPT.
}

\begin{abstract}
An autotrophic denitrification system was developed for treatment wastewater from steel industry. The aim was to evaluate the kinetics and capability of the system in reducing nitrate content in such industrial wastewater. The experiments were conducted in batch suspension and continuous runs. The denitrification kinetics in suspension runs obeys first order reaction with the rate constant $k_{1}$ and $k_{2}$ were determined to be 0.014 and $0.004 \mathrm{~g}-\mathrm{N} / \mathrm{m}^{3} . d$, respectively. The continuous runs used a column packed with mixture of granular sulfur and limestone. The microbes of Thiobacillus denitrificans were attached on the surface of granular sulfur in the form of biofilm. The biofilm thickness was investigated to be approximately $40 \mathrm{~m}$. The denitrification kinetics in the packed column obeys half-order reaction with the rate constant $k$ of $0.172 \mathrm{~g}-\mathrm{N}^{1 / 2} \cdot \mathrm{m}^{1 / 2} /(\mathrm{kg}-\mathrm{S}$.d). The lower denitrification extent of industrial wastewater compared with the synthetic wastewater might be due to the lack of alkalinity.
\end{abstract}

Keywords: Autotrophic denitrification, sulfur, packed column, thiobacillus denitrificans.

\section{Introduction}

Increasing of nitrate pollution in river water is partly contributed by industrial activities. In many developing countries, problem of technology and cost for wastewater treatment provide discharge of nitrate from industry is identified occasionally higher than the level which is regulated by the government. To eliminate the problem, development of simple and economical wastewater treatment technology is necessary. Nitrate removal (hereafter denitrification) from industrial wastewater containing high organic carbon, is effectively performed by heterotrophic bacteria. However, in case of organic carbon content is a very low, chemical such as methanol have to be added to the wastewater to promote the heterotrophic denitrification. Therefore, the cost of chemicals lessened the effectiveness of this system. For such wastewater, simple and economical denitrification using autotrophic bacteria is applicable. Thiobacillus denitrificans is typical autotrophic bacteria which can reduce nitrate by employing various sulfur compounds as an electron donor without adding any organic carbons. Elemental sulfur is reported as the most economical electron donor because it can easily obtained and low price (Driscoll and Bisogni, 1978).

Autotrophic denitrification using elemental sulfur in a packed column has been reported for treatment nitrate-contaminated groundwater (Schippers et al., 1987). The ability of such packed column for removing nitrate from nitrified landfill leachate has also been reported (Hano et al., 1996; Koenig and Liu, 1996). However, very little study reported on denitrification of industrial wastewater. In this study, we proposed autotrophic denitrification system for treatment nitrate-contaminated industrial wastewater. The basic kinetics of the denitrification reaction was elucidated both in batch suspension and continuous packed column runs. Furthermore, the capability of the system in treating the wastewater was pointed out.

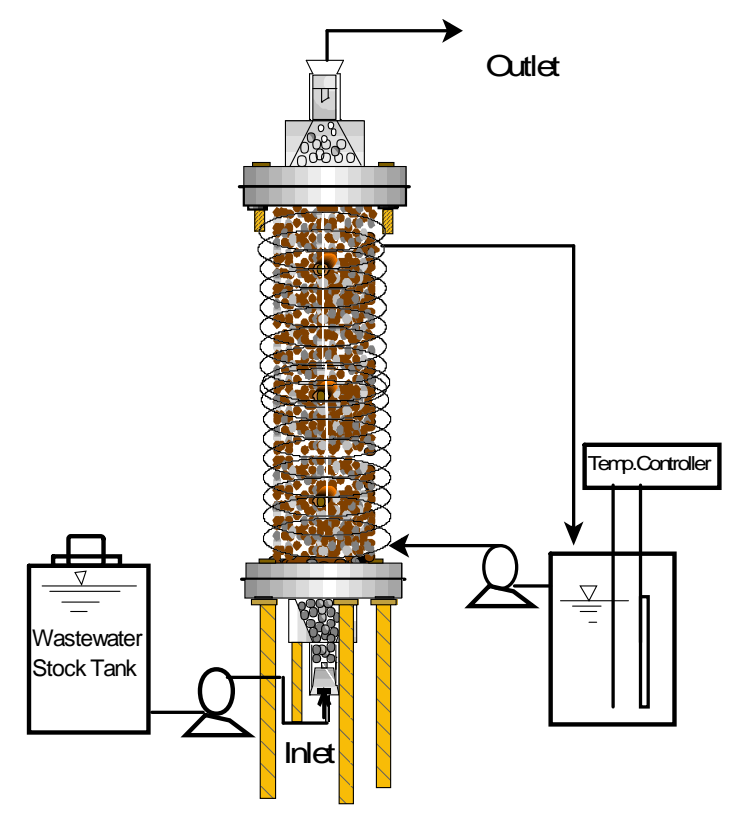


Fig.1 : Sulfur and limestone packed column in the experimental apparatussystem

\section{Materials and methods}

\subsection{Acclimation of microbe}

To obtain microbes of Thiobacillus denitrificans, activated sludge taken from terminal treatment plant of separate sewer system was acclimatized by feeding synthetic wastewater under anaerobic condition for a long time. The composition of the synthetic wastewater used for acclimation is described in Table 1. Sodium thiosulfate pentahydrate was used as an electron donor and $\mathrm{pH}$ during the acclimation was maintained neutral by adding phosphate buffer.

\subsection{Industrial wastewater characteristic}

The industrial wastewater to be treated was supplied by steel industry located in Japan. It was come from an effluent of nitric acid rinsing process after passing the coagulation and sedimentation treatment. The composition of the industrial wastewater is described in previous paper (Rudi, et al., 2000). The main composition is nitrate and fluoride with concentration of 430 $\mathrm{g}-\mathrm{N} / \mathrm{m}^{3}$ and $890 \mathrm{~g}-\mathrm{F} / \mathrm{m}^{3}$ respectively. Trace amount of heavy metals such as nickel and chrome is also contained. In order to eliminate inhibition level during denitrification experiments, the industrial wastewater was diluted 10 -fold by tap water. When the experiments were performed to elucidate the kinetics of denitrification, phosphate buffer and any inorganic minerals as that used for acclimation was added to the industrial wastewater.

Table 1:Composition of synthetic wastewater for culture acclimation.

\begin{tabular}{|l|c|}
\hline \multicolumn{1}{|c|}{ Components } & Concentration $\left[\mathbf{g} / \mathbf{m}^{3}\right]$ \\
\hline Nitrogen source & \\
$\mathrm{KNO}_{3}$ & 144 \\
Inorganic minerals & 148 \\
$\mathrm{NH}_{4} \mathrm{Cl}$ & 122 \\
$\mathrm{MgSO}_{4} .7 \mathrm{H}_{2} \mathrm{O}$ & 10 \\
$\mathrm{FeSO}_{4} .7 \mathrm{H}_{2} \mathrm{O}$ & 1000 \\
$\mathrm{NaHCO}_{3}$ & 1500 \\
$\mathrm{Buffer}^{\mathrm{KH}_{2} \mathrm{PO}_{4}}$ & 3500 \\
$\mathrm{Na}_{2} \mathrm{HPO}_{4} .12 \mathrm{H}_{2} \mathrm{O}$ & \\
\hline
\end{tabular}

\subsection{Batch denitrification in suspension runs}

The batch denitrification runs was performed in $300 \mathrm{ml}$ Erlenmeyer flask by adding $100 \mathrm{ml}$ of industrial wastewater to $100 \mathrm{ml}$ of acclimatized microbe of Thiobacillus denitrificans. Sodium thiosulfate pentahydrate was used as an electron donor. To prevent air enter into the flask, the flask was equipped with rubber lid. The flask was then shaken at $30^{\circ} \mathrm{C}$ for 6 hours. Samples were taken at a period of 1 hr. After sampling, nitrogen gas was purged into the flask for 3 minutes to provide anaerobic condition during denitrification.

\subsection{Continuous operation of packed column}

A column made from acrylic pipe, $42 \mathrm{~mm}$ in diameter and $620 \mathrm{~mm}$ in height, was filled with mixture of granular sulfur and limestone (Fig. 1). Limestone was used to suppress the decrease of alkalinity caused by releasing proton during autotrophic denitrification. The volume ratio of sulfur to limestone was set 1:1. Both sulfur and limestone particle sizes were in the range of 2.8 to $4 \mathrm{~mm}$. The weight of sulfur packed in the column was $423 \mathrm{~g}$. Six sampling ports were installed at the wall of the column with interval distance of $80 \mathrm{~mm}$. After denitrification activity of the acclimatized microbe became appreciable, the microbe was loaded to the column and recycled through the column to settle the microbe on the granules. At the beginning of continuous column operation, the synthetic wastewater was fed up into the column at low flow rate to avoid the microbe washout from the column. After biofilm appeared and denitrification became stable, the feed was changed to the industrial wastewater. Samples were taken from the inlet and outlet as well as from the sampling ports along the column height. The temperature was maintained at $30^{\circ} \mathrm{C}$ in all runs.

\section{$2.5 \quad$ Analyses}

Nitrate, nitrite and sulfate were analyzed by using ion chromatography model dionex AS4A-SC, equipped with CD and UV-detector. $\mathrm{pH}$ was measured by using $\mathrm{pH}$ meter model TOA-HM 5B. The alkalinity of the wastewater was determined by titration method using 0.01 $\mathrm{M} \mathrm{H}_{2} \mathrm{SO}_{4}$. Methyl red-bromcresol green solution was used as the indicator.

\section{Results and Discussion}

\subsection{Kinetics of denitrification}

The denitrification kinetics of industrial wastewater was evaluated both in batch suspension and packed column runs. Figure 2 
shows the basic behaviour of denitrification in batch suspension runs. Nitrate decreased rapidly to $8 \mathrm{~g}-\mathrm{N} / \mathrm{m}^{3}$ at 1 hour, while nitrite as an intermediate was produced and accumulated at a maximum concentration of about $20 \mathrm{~g}-\mathrm{N} / \mathrm{m}^{3}$. After 2 hours, nitrate concentration could be maintained at a concentration almost 0 and nitrite gradually decreased to almost 0 at the end of experiment. Sulfate was produced in accordance with nitrogen removed.

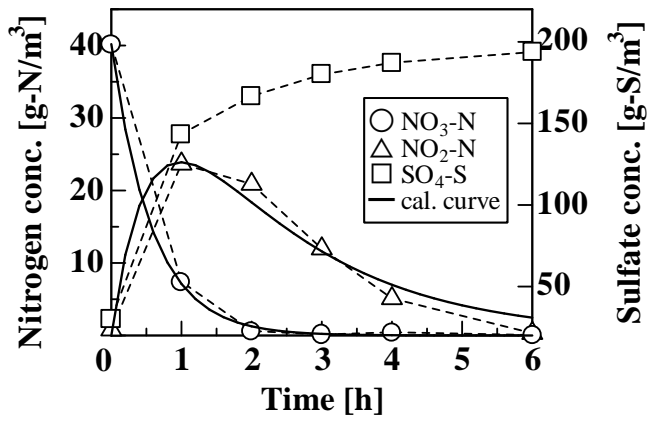

Fig. 2 : Denitrification of industrial wastewater in batch suspension run ( $\mathrm{pH} 7$, MLSS $3050 \mathrm{~g} / \mathrm{m}^{3}$ ).

In denitrification reaction with nitrate as nitrogen source, nitrate is firstly reduced to nitrite by the rate constant $k_{1}$ and nitrite to nitrogen gas by the rate constant $k_{2}$ as a consecutive reaction in Eq. (1). We assumed that both nitrate and nitrite reduction in denitrification using thiosulfate as an electron donor follows first order reaction, the nitrate and nitrite concentration changing by time could be expressed by Eqs. (2) and (3).

$$
\begin{aligned}
& \mathrm{NO}_{3}{ }^{-} \stackrel{k_{1}}{\longrightarrow} \mathrm{NO}_{2}{ }^{-} \stackrel{k_{2}}{\longrightarrow} \mathrm{N}_{2} \\
& -\frac{d C_{\mathrm{NO}_{3}}}{d t}=k_{1} C_{\mathrm{NO}_{3}} \\
& \frac{d C_{\mathrm{NO}_{2}}}{d t}=k_{1} C_{\mathrm{NO}_{3}}-k_{2} C_{\mathrm{NO}_{2}} \\
& \text { ( } 3
\end{aligned}
$$

By integration of Eqs. (2) and (3) the change concentration of nitrate and nitrite with time to be

$$
\begin{aligned}
& C_{\mathrm{NO}_{3}}=C_{\mathrm{NO}_{3}} e^{-k_{1} t} \\
& C_{\mathrm{NO}_{2}}=C_{\mathrm{NO}_{3}} \frac{k_{1}}{k_{2}-k_{1}}\left(e^{-k_{1} t}-e^{-k_{2} t}\right)
\end{aligned}
$$

where $C_{\mathrm{NO}}$ and $C_{\mathrm{NO}}$ o is nitrate concentration at $t$ and $0 \mathrm{~h}, C_{\mathrm{NO} 2}$ and $\mathrm{C}_{\mathrm{NO}} \mathrm{o}$ is nitrite concentration at $t$ and 0 h. By computer simulation using Eqs. (4) and (5), the rate constant $k_{1}$ and $k_{2}$ can be calculated and equals 0.014 and 0.004 $\mathrm{g}-\mathrm{N} /(\mathrm{g}-\mathrm{SS} . \mathrm{d}$.), respectively. Consequently, it is clear that accumulation of nitrite is caused by the reduction rate of nitrate to nitrite higher than nitrite to nitrogen gas.

Figure 3 represents the nitrate, nitrite and sulfate distribution in the column under hydraulic retention times of 3.5 hours. Nitrate concentration decreased along the axial distance of the packed column and almost zero at the effluent. Sulfate gradually increased as the denitrification proceed. The decrease of nitrate was linier at the inlet column till the middle part of the column and become slow when it reached the bottom.

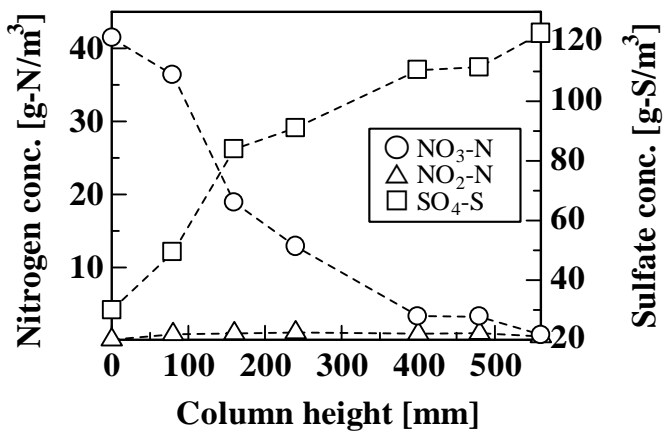

Fig. 3 : Denitrification of industrial wastewater in packed column run. HRT 3.5hours.

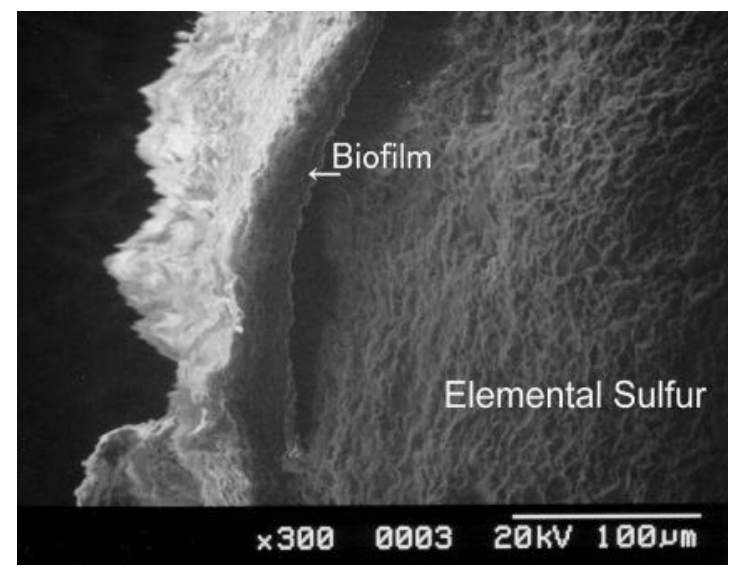

Picture 1 : Biofilm attached on the surface of elemental sulfur.

It is reported that the denitrification reaction in the packed column was half-order due to the diffusion of nitrate in biofilm control the over all reaction (Harremoes, 1976). To determine the reaction order of the denitrification, we investigated the biofilm attached on the surface of elemental sulfur during the experiments. Picture 1 shows the Scanning Electro Micrograph (SEM) of granular sulfur sampled 
from the column. The microbe was clearly formed biofilm in significant thickness of approximately $40 \mathrm{~m}$. Therefore, we arranged the experimental results following half-order model equation. By assuming that the distribution of sulfur particles is similar along the column, the half-order equation can be modified by converting reaction time $t$ to $W_{s} / v_{o}$ in Eq. (6).

$$
\sqrt{C_{\mathrm{NO}_{3}}}=\sqrt{C_{\mathrm{NO}_{3}}}-\frac{1}{2} k \frac{W_{s}}{v_{0}}
$$

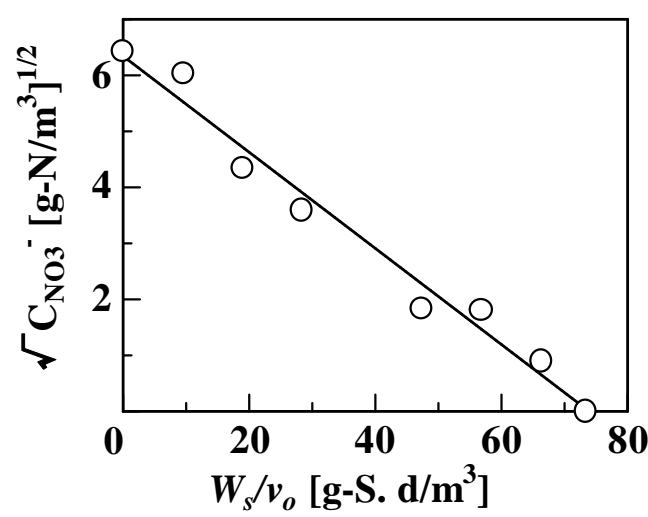

Fig. 4 : Correlation between square root of nitrate and sulfur particle weight in the packed column.

where $W_{s}$ is sulfur particles weight and $v_{0}$ is influent flow rate. Figure 4 shows the correlation between nitrate concentration in the column and $W_{s} / v_{o}$. The amount of nitrate decreased was clearly proportional with the weight of sulfur particles. From this finding, in order to achieve the high denitrification efficiency at given sulfur particles size, the amount of sulfur particles should be maximized. The half-order reaction rate constant was calculated from the slope of nitrate concentration change in Fig. 4 and equals $0.172 \mathrm{~g}-\mathrm{N}^{1 / 2} \cdot \mathrm{m}^{1 / 2} /(\mathrm{kg}-\mathrm{S} . \mathrm{d})$.

\subsection{Stoichiometry of autotrophic denitrification}

In the autotrophic denitrification using Thiobacillus denitrificans, sulfate is produced in accordance with nitrogen removed. Figure $\mathbf{5}$ shows the sulfate produced and nitrogen removed in both batch suspension and continues packed column runs. The slope of the correlating line was about 1.9 and 0.98 respectively. In the denitrification reaction using Thiobacillus denitrificans, it is reported that the mol ratio of sulfate produced to nitrogen removed was1.69 when thiosulfate was used as an electron donor (Bisogni and Driscoll, 1977). However, when the electron donor was elemental sulfur, the ratio was 1.114 (Driscoll and Bisogni, 1978). Equations (7) and (8) illustrate the stoichiometric equations for the autotrophic denitrification. The results in our experiments are fairly close to the value reported in those literatures. This finding suggests that the dominant microbe exist in our experiments is Thiobacillus denitrificans. This microbe is well known as the one which has higher resistant towards any pollutants such as heavy metals (Claus and Kutzner, 1985). Therefore, it is suitable for treatment industrial wastewater involving many kinds of pollutants.

$0.844 \mathrm{~S}_{2} \mathrm{O}_{3}{ }^{2-}+\mathrm{NO}_{3}{ }^{-}+0.434 \mathrm{H}_{2} \mathrm{O}+0.347 \mathrm{CO}_{2}+$ $0.086 \mathrm{HCO}_{3}{ }^{-}+0.0865 \mathrm{NH}_{4}+1.689 \mathrm{SO}_{4}{ }^{2}+0.5 \mathrm{~N}_{2}$ $+0.0865 \mathrm{C}_{5} \mathrm{H}_{7} \mathrm{O}_{2}$ (biomass) $+0.697 \mathrm{H}^{+}$ (7)

$1.114 \mathrm{~S}+\mathrm{NO}_{3}-0.699 \mathrm{H}_{2} \mathrm{O}+0.337 \mathrm{CO}_{2}+$ $0.084 \mathrm{HCO}_{3}{ }^{-}+0.0842 \mathrm{NH}_{4}{ }^{+} \rightarrow 1.114 \mathrm{SO}_{4}{ }^{2-}+0.5 \mathrm{~N}_{2}$

$+0.0842 \mathrm{C}_{5} \mathrm{H}_{7} \mathrm{O}_{2}$ (biomass) $+1.28 \mathrm{H}^{+}$

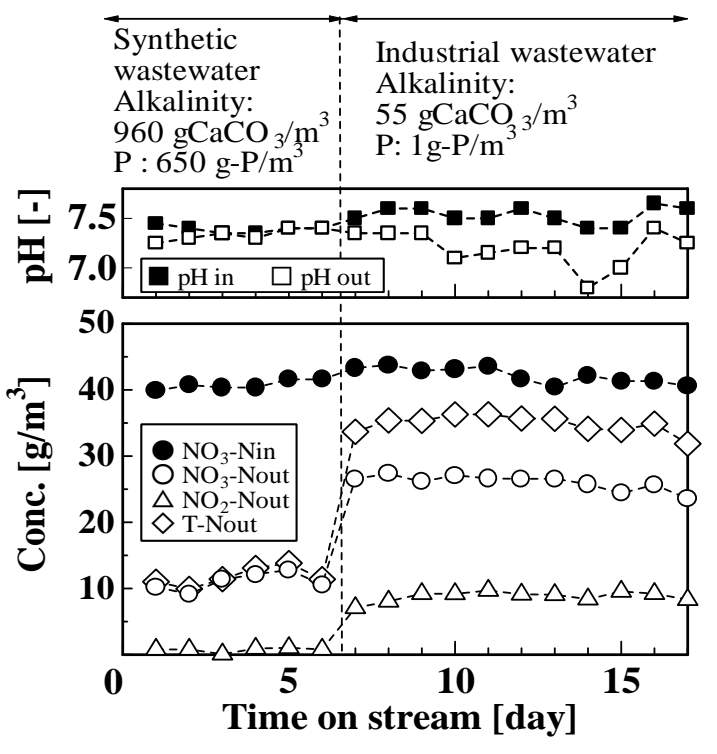

Fig. 5 : Correlation between nitrogen removed and sulfate produced.

\subsection{Performance of packed column in treating industrial wastewater}

Performance of the packed column in treating the industrial wastewater was evaluated by comparing with the treatment performance of synthetic wastewater which involved nitrate and some minerals including phosphate buffer as that used for acclimation. The industrial wastewater was prepared by addition only $\mathrm{KH}_{2} \mathrm{PO}_{4}(1 \mathrm{~g}-\mathrm{P} / \mathrm{m} 3)$. The wastewater was fed to the packed column at flow rate of $6 \mathrm{~cm}^{3} / \mathrm{min}$. after running with the synthetic wastewater. The results were shown in Fig. 6. After switching to 
the industrial wastewater, the effluent of nitrate and nitrite nitrogen (hereafter refer to as T-N) drastically increased in indicating a significant decrease of denitrification extent. Nitrite increased initially and then almost constant till the end of the experiment. The range of $\mathrm{pH}$ during these runs and the difference of phosphorus concentration between the synthetic and industrial wastewater did not affect the denitrification rate (Rudi et al., 2000). The influent alkalinity in the run using industrial wastewater was $55 \mathrm{~g}-\mathrm{CaCO}_{3} / \mathrm{m}^{3}$ whereas nitrate was $40 \mathrm{~g} / \mathrm{m}^{3}$. It is known that denitrification reaction using autotrophic bacteria consumes alkalinity.

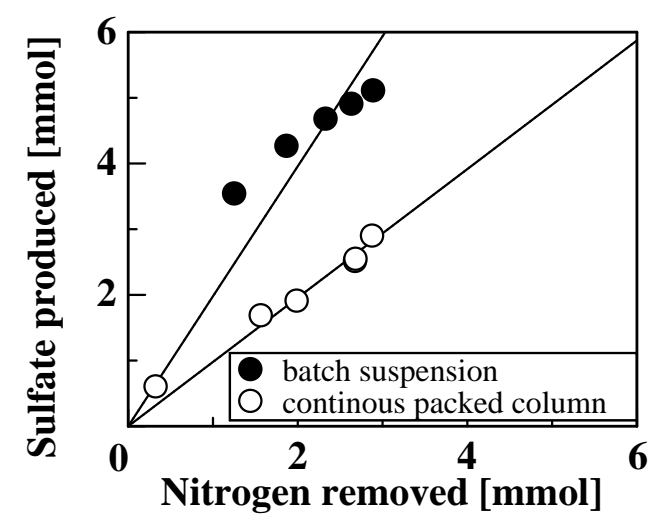

Fig.6: Continuous denitrification of industrial wastewater under low initial alkalinity. HRT $2.3 \mathrm{~h}$.

According to the Eq. (2), the consumption of alkalinity can be calculated $4.38 \mathrm{~g}$ alkalinity (as $\mathrm{CaCO}_{3}$ ) per $\mathrm{g}$ nitrate reduced. Therefore, it is difficult to provide high denitrification extent without supplying alkalinity. The limestone packed in the column was desirable to occupy the alkalinity consumption. From the fact that denitrification rate of industrial wastewater was very low, we suggested the supplying alkalinity by limestone was insufficient. Hence, we analyzed the substances deposited on the surface of limestone after and before being used in the packed column run by Energy Dispersive X-ray (EDX). Table 2 shows that composition of calcium on the surface of limestone after run was decreased due to the formation of phosphorus, sulfur and ferrous deposits. Consequently, we consider that the formation of the deposits on the surface of limestone may decrease its capability in supplying alkalinity.

Table 2 : Deposits on the surface of limestone, before and after they were used in packed column.

\begin{tabular}{|l|r|r|}
\hline Substances & $\begin{array}{c}\text { Before use } \\
\%\end{array}$ & $\begin{array}{c}\text { After used } \\
\%\end{array}$ \\
\hline $\mathrm{Ca}$ & 88.52 & 25.32 \\
$\mathrm{P}$ & 8.15 & 34.93 \\
$\mathrm{~S}$ & 2.84 & 37.34 \\
$\mathrm{Fe}$ & 0.49 & 2.40 \\
\hline
\end{tabular}

In order to confirm the effect of alkalinity, we treated the synthetic and industrial wastewater with the same alkalinity. The synthetic wastewater to be used was the same with that used in Fig. 6, except without addition phosphate buffer. The phosphorus concentration was set at $1 \mathrm{~g}-\mathrm{P} / \mathrm{m}^{3}$. The addition of minerals into the industrial wastewater was the same concentration with that in the synthetic wastewater. Figure 7 shows the comparison of the denitrification between these wastewaters. Almost the same denitrification extent in both wastewaters confirmed that insufficient alkalinity is the main reason of the decrease of denitrification extent in Fig.6.

\begin{tabular}{l|l}
\hline Synthetic & Industrial wastewater \\
wastewater & Alkalinity: \\
Alkalinity: & 600 gCaCO \\
$630 \mathrm{gCaCO}_{3} / \mathrm{m}^{3}$ & $\mathrm{P}: 1 \mathrm{~g}-\mathrm{P} / \mathrm{m}^{3}$ \\
$\mathrm{P}: 1 \mathrm{~g}-\mathrm{P} / \mathrm{m}^{3}$ &
\end{tabular}

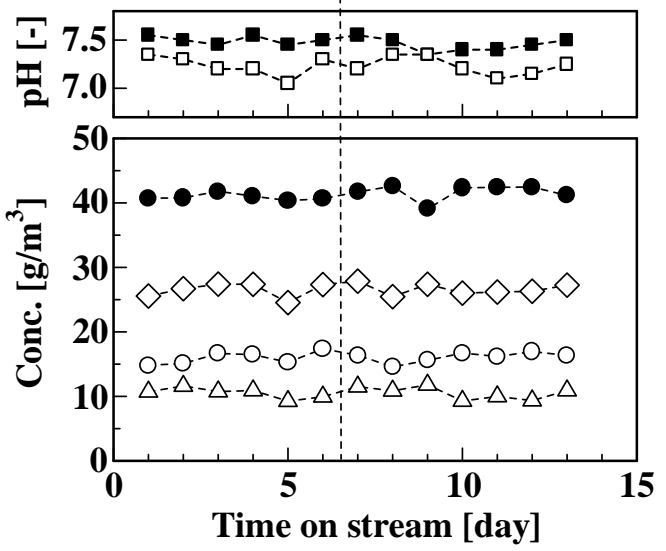

Fig.7 : Continuous denitrification of industrial wastewater under high initial alkalinity. HRT 2.3 h. Symbols are the same as that in Fig. 6.

\subsection{Effect of any component content in the industrial wastewater on denitrification}

As mentioned above, the industrial wastewater contains high concentration of nitrate, fluoride and trace amount of heavy metals. To clarify the effect of such components, the batch experiments in suspension runs were conducted by mixing the synthetic wastewater and the industrial wastewater. The industrial wastewater to be used in this experiment was prepared without dilution. The nitrate concentration in the synthetic wastewater was 
adjusted the same with that on the industrial wastewater. The fraction of industrial wastewater and synthetic wastewater was changed from 0 to $100 \%$ by volume. The initial alkalinity was $900 \mathrm{~g}-\mathrm{CaCO}_{3} / \mathrm{m}^{3}$ in all runs. The results were shown in Fig. 8. As shown in this figure, T-N removal rate was almost the same in all fractions suggesting that any components existing in the industrial wastewater

At the separate batch experiments, we investigated the effect of initial nitrate concentration, fluoride and nickel on denitrification of synthetic wastewater. As the results, these components at a level close to the concentration in the industrial wastewater did not inhibit the denitrification (data not shown). Consequently, we concluded that no inhibitors present in the industrial wastewater. From these findings, we considered if the alkalinity is sufficient, the autotrophic denitrification of the industrial wastewater in packed column is possible even without dilution.

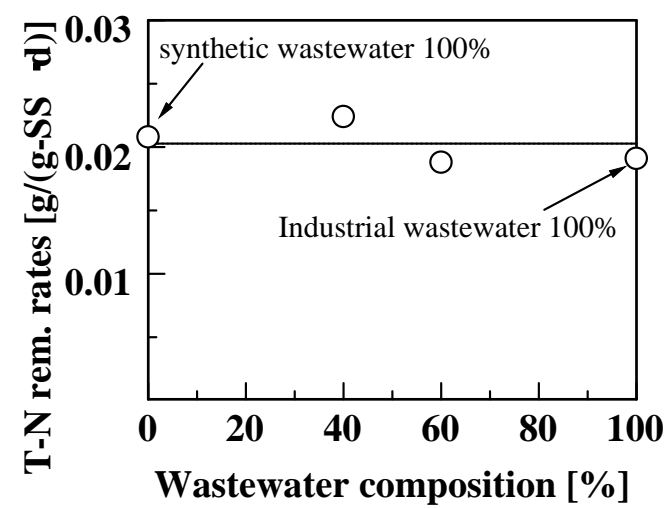

Fig. 8 : Effect of industrial wastewater on denitrification in batch suspension runs. $\mathrm{pH} 7$, MLSS $9300 \mathrm{~g} / \mathrm{m}^{3}$.

\section{Conclusions}

Denitrification system using autotrophic bacteria could successfully remove nitrate from industrial wastewater. The kinetics of the denitrification reaction in suspension runs obeyed first order reaction. The stoichiometry of nitrogen removed with respect to sulfate produced was comparable to that reported by the other authors. In the continuous runs using sulfur and limestone packed column, microbe of Thiobacillus denitrificans formed biofilm on the surface of granular sulfur with the thickness of about $40 \mathrm{~m}$. The decrease of nitrate along the axial distance of the packed column obeyed half-order kinetics, and was proportional with the weight of the granular sulfur. The components content in the industrial wastewater did not inhibit the denitrification. Lower denitrification extent of industrial wastewater than that of synthetic wastewater might be due to the lack of alkalinity. Finally, we concluded that the denitrification of industrial wastewater is possible even without dilution, if the alkalinity is sufficient.

\section{References}

1. Bisogni, J. J. and C. T. Driscoll, Denitrification using Thiosulfate and Sulfide, J. Env. Eng., 1977, Vol. 103 pp 593-604.

2. Driscoll, C. T., J. J. Bisogni, The Use of Sulfur and Sulfide in Packed Bed Reactors for Autotrophic denitrification, J. WPCF, 1978, Vol.50 pp 569-576.

3. Claus, G. and H. J. Kutzner; Autotrophic Denitrification by Thiobacillus denitrificans in a Packed Bed Reactor, Applied Microbiology and Biotechnology, 1985, Vol.22, pp 289-296.

4. Hano, T., H. Takanashi, M. Hirata and S. Ohara, Nitrogen Removal from Landfill Leachate with Autotrophic Bacteria, Proceeding of Reg. Symp. on Chem. Eng, Jakarta, 1996.

5. Schippers, J. C., J.C. Kruithof, F. G. Mulder and J. W. van Lieshout; Removal of Nitrate by Slow Sulphur/Limestone Filtration, Aqua, 1987, No.5 pp 274-280.

6. Koenig and L. H. Liu, Autotrophic Denitrification of Landfill Leachate Using Elemental Sulphur, Water Science and Technology, 1996, Vol. 34, No. 5-6 pp 469-476.

7. Harremous, P., The Significance of Pore Diffusion to Filter Denitrification, J. WPCF., 1976, Vol. 48 No.2 pp 377-387.

8. Rudi, N., H. Takanashi, M. Hirata and T Hano, Denitrification of Wastewater with Simple Biological Method, Proceeding of the First Joint China/Japan Chemical Engineering Symposium, Beijing, 2000, Vol.11 pp 68-73. 